\title{
Transfer of Biological Soil Suppressiveness Against Heterodera schachtii
}

\author{
A. Westphal and J. O. Becker
}

Department of Nematology, University of California, Riverside.

Accepted for publication 27 December 1999.

\section{ABSTRACT}

Westphal, A., and Becker, J. O. 2000. Transfer of biological soil suppressiveness against Heterodera schachtii. Phytopathology 90:401-406.

Heterodera schachtii-suppressive soil at a rate of either 1 or $10 \%$ (dry $\mathrm{wt} / \mathrm{wt}$ ) transferred suppressiveness against the beet cyst nematode to fumigated field plots when mixed into the upper 10-cm soil layer. Soil suppressiveness was established after 1 month of moist fallow and 77 days of Swiss chard cropping in the $10 \%$ transfer treatment and after 230 days in the $1 \%$ transfer treatment. The number of infective second-stage juveniles (J2) of $H$. schachtii, monitored initially at 150 degree-day intervals and later at 300 degree-day intervals, indicated the status of suppres- siveness in the different treatments during the cropping period. In a greenhouse experiment, amending fumigated field soil with $0.1,1.0$, or $10 \%$ suppressive soil, suppressed multiplication of $H$. schachtii when soils were infested with an additional 5,000 J2. In a second greenhouse experiment, a fumigated sandy loam amended with 10 or $25 \%$ suppressive soil and a fumigated loam amended with $25 \%$ suppressive soil had significantly fewer eggs per cyst than the nonamended fumigated treatments when $1,000 \mathrm{~J} 2$ were added.

Additional keywords: Beta vulgaris, nematode infectivity, population dynamic.
Transferability is an important characteristic of biological soil suppressiveness against soilborne plant pathogens (3). Suppressive soil $(1 \%)$, together with $1 \%$ alfalfa meal, transferred suppressiveness against potato scab, caused by Streptomyces scabies, into naturally infested conducive soil (18). Suppressive soil $(0.5 \%)$ provided substantial restoration of soil suppressiveness in fumigated field plots against take-all disease of wheat (21). In successive dilutions, an equivalent of $1 \mathrm{ppm}(\mathrm{vol} / \mathrm{vol})$ of suppressive soil transferred suppressiveness against Fusarium wilt to a soil mixture, if intermediate dilution mixes were cultivated during the 3-month incubation between dilutions (1). Amendments of biocidally treated, disease-conducive soils or substrates with 1 to $10 \%$ disease-suppressive soils have been reported to transfer disease suppressiveness $(2,7,9,10,26)$. Although a few nematode-suppressive soils have been studied intensively(15), transferability of soil suppressiveness against plant-parasitic nematodes has not received much attention. In a greenhouse study, the 20- to $53-\mu \mathrm{m}$ soil fraction of $5 \mathrm{~kg}$ of Heterodera avenae-suppressive soil from England was mixed into $2 \mathrm{~kg}$ of naturally cereal cyst nematode-infested South Australian soil. This resulted in infection of $H$. avenae females by fungal female parasites and, consequently, in $H$. avenae suppression (22). Ring nematode-suppressive soil $(5 \%)$ added to pasteurized soil resulted in nematode suppression compared with the pasteurized and nonamended control (16).

The current study focused on a beet cyst nematode-suppressive soil at the agricultural research station, University of California, Riverside. In 1975, field 9E had been amended with $H$. schachtiiinfested field soil from a sugar beet-growing area near Moreno Valley, CA, and had been cropped continuously with host plants of the nematode. After initial establishment of the nematodes and significant crop-yield reductions due to their parasitic activity, the beet cyst population declined and has remained at a low level for at least a decade (I. J. Thomason, personal communication; A. Westphal, unpublished data). Previous research demonstrated the biological nature of this soil suppressiveness (25). The objective

Corresponding author: J. O. Becker; Email address: ole.becker@ucr.edu

Publication no. P-2000-0210-02R

(c) 2000 The American Phytopathological Society of this study was to determine whether the soil suppressiveness can be transferred into $H$. schachtii-conducive fumigated field plots. During the entire cropping period, the infectivity of $H$. schachtii second-stage juveniles (J2) was monitored. In addition, in greenhouse trials, we investigated whether suppressiveness of $9 \mathrm{E}$ soil was transferable to other fumigated soils. Preliminary results of this project have been published $(23,24)$.

\section{MATERIALS AND METHODS}

Transfer of suppressiveness to fumigated field plots. The trial was conducted in $H$. schachtii-suppressive field $9 \mathrm{E}$ at the agricultural research station, University of California, Riverside. After a green-manure crop of canola (Brassica napus L.), the Hanford fine sandy loam soil (60.9\% sand, $29.6 \%$ silt, and $9.5 \%$ clay, $\mathrm{pH} 8$ ) had an initial $H$. schachtii population density of 13.5 eggs per $\mathrm{g}$ in the top $10 \mathrm{~cm}$ of soil. The plot area was chiseled to a depth of $45 \mathrm{~cm}$ in a criss-cross pattern diagonal to the orientation of the seedbeds at the end of March 1996. The area was disced and N-P-K fertilizer $(15-15-15 ; 336 \mathrm{~kg} / \mathrm{ha})$ was incorporated with a cultimulcher. Seedbeds were prepared on $75-\mathrm{cm}$ centers, allowing two seedbeds for each experimental plot. One of these rows was harvested after 77 days ("harvest row"), and the second one was used for monitoring the infectivity of $H$. schachtii and was harvested after 230 days ("sample row"). One border row separated the plots from one another. The trial was arranged in a randomized complete block design (block length $5.1 \mathrm{~m}$ ) with six treatments and five replicates.

Four of six plots per block were hot-gas fumigated with methyl bromide (336 kg/ha) (11) with a commercial applicator (TriCal Inc., Hollister, CA) to reduce the soil suppressiveness to nondetectable levels (25). Suppressive 9E soil was randomly collected, passed through a 6-mm screen, and thoroughly mixed. Aliquots of this suppressive soil were sprinkled onto the seedbeds of two of the fumigated plots of each block at a rate of 1 or $10 \%$ (dry wt/wt of the upper 10-cm soil layer) and were rototilled into the upper $10 \mathrm{~cm}$. The other four plots in each block were rototilled without soil amendment. All plots were kept moist at a water potential of -20 to $-30 \mathrm{kPa}$ with a low-volume drip-irrigation system.

During May, 1 month after amendment of plots, one nonfumigated, one fumigated, and both of the transfer treatments were 
infested with greenhouse-reared $H$. schachtii. In each plot, both seedbeds were infested at 10 planting sites in $30-\mathrm{cm}$ intervals along the seedbed center. For each planting site, a 10-cm-deep soil core was taken with a bucket auger $(7.6 \mathrm{~cm}$ in diameter). The soil was placed in a plastic bag (2-liter capacity) that contained $\approx 446$ cysts of $H$. schachtii with $\approx 50,000$ eggs in $250 \mathrm{~g}$ of a sandy potting soil. The nematodes had been raised in this potting soil on sugar beets in the greenhouse. After thoroughly mixing the soil core with the greenhouse inoculum, the infested soil was placed in the original hole. A noninfested fumigated (conducive) control and a noninfested, untreated (suppressive) control received $250 \mathrm{~g}$ of the same sandy potting soil that had been the substrate of $H$. schachtii-free sugar beets for the same time as the inoculum potting soil.

One month after infestation, one 5-week-old seedling of Swiss chard (Beta vulgaris subsp. cicla (L.) W. Koch 'Large White Ribbed'; Lockhart Seeds Inc., Stockton, CA) was planted in the middle of each of the planting sites in all plots. During the cropping period, insect control was conducted with spray applications of imidachloprid (52.5 $\mathrm{g}$ a.i./ha) as needed. After 77 days (1,350 degree days [DD], $8^{\circ} \mathrm{C}$ basal temperature) (8), the plant tops of the harvest row were cut off at ground level, and oven dry weights were determined. The root systems with the adhering soil core were recovered with a bucket auger $(7.6 \mathrm{~cm}$ in diameter) to a depth of $10 \mathrm{~cm}$. Cysts and soil were thoroughly shaken and washed with water from the roots over a 20 -mesh screen $(0.83 \mathrm{~mm})$ nested on a 100 -mesh screen $(0.15 \mathrm{~mm})$. Roots were oven dried and weighed. The recovered wash-off from the 100-mesh screen was mixed back into the rest of its original soil core. A 350-g subsample from the mixed soil core was used for cyst extraction with a modified Fenwick flotation can (6) with an extraction efficiency of $\approx 80 \%$ from moist soil. The cysts were counted and broken in a tissue homogenizer for egg enumeration. The plants of the sample row were trimmed to $5-\mathrm{cm}$ stubble and cropped for a total of 230 days until February 1997. Three applications of $26 \mathrm{~kg} / \mathrm{ha}$ and three applications of $52 \mathrm{~kg} / \mathrm{ha}$ of a N-P-K fertilizer (15-30-15, Miracle Gro) were dissolved in water and supplied by overhead sprinkling as needed. Plants from the sample row were harvested as described above. For both harvests, the numbers of cysts per root dry weight and the number of eggs per cyst were determined.

Monitoring the infectivity of $\boldsymbol{H}$. schachtii in field plots. During the entire length of the field trial, the nematode infectivity was monitored with a bioassay, initially in 150-DD intervals and then in 300-DD intervals, based on the soil temperature at a depth of $10 \mathrm{~cm}$. For the first nine sampling dates, a cork borer $(17 \mathrm{~mm}$ in diameter) was inserted diagonally into the root zone $\approx 2.5 \mathrm{~cm}$ from the plant stem and $10 \mathrm{~cm}$ deep in each of the 10 planting sites per plot. The soil cores of each plot were pooled, mixed, and used for a growth-chamber bioassay. For the final five sampling dates, one plant per sampling date was chosen at random from the sample row of each plot and carefully removed. The roots were separated from the cysts and soil as described before. At each sampling, the recovered soil samples were divided into three small subsamples (60- to 100 -g total weight, according to availability of total soil sample) and were placed in 250-ml translucent polystyrene containers. All samples per sampling date were adjusted to a uniform moisture content; typically between 11 and $16 \%$. After 1 day for moisture equilibration, each of the containers was seeded with one surface-sterilized (5 min in 20\% commercial bleach solution, $5.25 \%$ $\mathrm{NaOCL}$ ) radish seed (Raphanus sativus L. 'Cherry Belle'; FerryMorse, Fulton, KY). The containers were closed with a polyethylene lid to reduce evaporation and incubated for 3 days in a day and night cycle of 16 and $8 \mathrm{~h}$ at 28 and $23^{\circ} \mathrm{C}$, respectively, in an environmental growth chamber. The radish seedlings were recovered from the soil, and J2s in the roots were counted after staining (5). The detected numbers of $\mathrm{J} 2$ were reported per $\mathrm{cm}$ of root length.

Transfer of soil suppressiveness to fumigated, initially suppressive soil in greenhouse experiments. Soil was collected randomly from the upper 10-cm soil layer of $H$. schachtii-suppressive field 9E. After passing through a 6-mm screen and mixing with silica sand $(10: 1, \mathrm{wt} / \mathrm{wt})$, one part of the soil was fumigated with methyl iodide (690 kg/ha) (4), and the other part was left untreated. After aeration, fumigated soil was amended with $0.1,1.0$, or $10 \%$ (dry wt/wt) of nonfumigated, suppressive soil. Nonfumigated, suppressive soil and the fumigated equivalent served as the suppressive and conducive control, respectively. The soils were placed into $15-\mathrm{cm}$ pots (Western Pulp Products Company, Corvallis, OR) and arranged in a randomized complete block design with five replicates in the greenhouse at $24 \pm 3^{\circ} \mathrm{C}$ under ambient light. The trial was irrigated with tap water through a low-volume drip irrigation system (Netafim Irrigation Inc., Fresno, CA). After 1 month, the pots were each planted with one 5-week-old seedling of Swiss chard. Two weeks later, each pot was infested with 5,000 J2 of $H$. schachtii. After 11 weeks, plant tops were cut off at ground level and weighed after oven drying. Adhering soil and cysts were shaken and washed off the roots with water and added back into the remaining pot content. Cysts were extracted from a 350-g soil subsample and counted, and the number of eggs was determined. The remaining soil was stored for $\approx 1$ month in plastic bags at $24 \pm 3^{\circ} \mathrm{C}$. The soils were repotted in $15-\mathrm{cm}$ pots and planted with cabbage (Brassica oleracea L. 'Late Flat Dutch'; Lockhart Seeds). After 11 weeks, plant top dry weights and nematode populations were determined as described before. Both crops were fertilized with 50 $\mathrm{ml}$ of a nutrient solution (10 $\mathrm{g}$ of Miracle Gro N-P-K [15-30-15] fertilizer per 3.79 liters of water,) weekly.

Transfer of soil suppressiveness to $\boldsymbol{H}$. schachtii-free soil or different textured soil in greenhouse experiments. Three soils were chosen for a transfer experiment in a randomized complete block design with six replicates. The first test soil (9C) was a

TABLE 1. Harvest data and nematode populations after 77 and 230 days of Swiss chard growth in fumigated and Heterodera schachtii-infested plots amended with various amounts of nematode-suppressive $9 \mathrm{E}$ soil

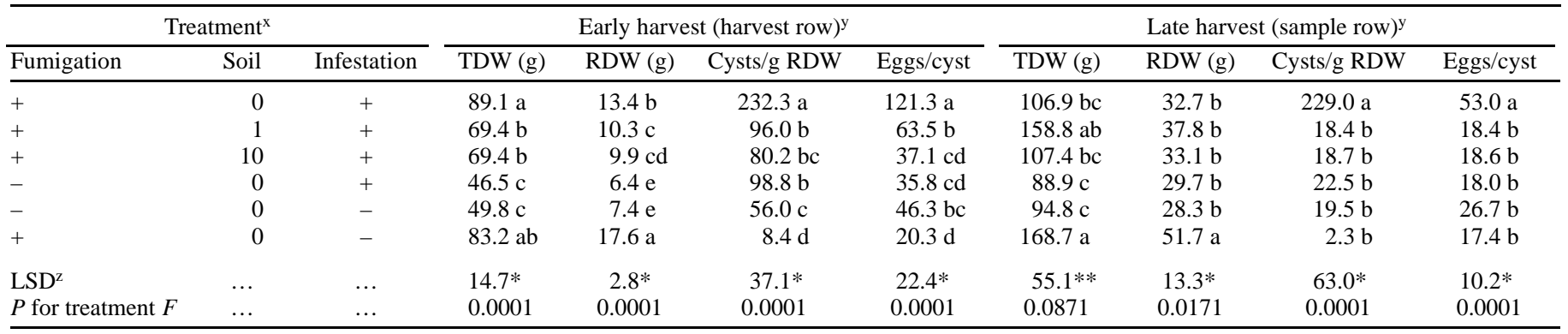

x Fumigation: +, preseason fumigation with methyl bromide at $336 \mathrm{~kg} / \mathrm{ha}$; -, untreated. Soil: amendment by percent suppressive soil mixed into upper 10 -cm soil layer (wt/wt). Infestation: +, potting mix contained 446 cysts ( $\approx 50,000$ eggs) of $H$. schachtii;,$- H$. schachtii-free potting mix.

${ }^{y}$ TDW = top dry weight; RDW = root dry weight. Plants in the harvest row were harvested after 1,350 degree days (DD); plants in the sample row were used to monitor the number of infective juveniles at the beginning of the cropping season and harvested at 2,550 DD. Means followed by the same letter within a column were not significantly different when tested with Fisher's least significant difference (LSD) at the $P$ value indicated.

$\mathrm{z} *$ and $* *$ indicate $P=0.05$ and 0.10 , respectively. 
Hanford coarse sandy loam soil (56\% sand, 24\% silt, $20 \%$ clay, $\mathrm{pH}$ 7.4) collected from field $9 \mathrm{C}$ on the agricultural research station, University of California, Riverside. This field was $\approx 200 \mathrm{~m}$ from $H$. schachtii-suppressive field 9E, separated by a jojoba orchard (Simmondsia chinensis (Link) C. Schneider). Field 9C had been cropped with various vegetable, nonhost crops of $H$. schachtii for the previous five years and with a low frequency of crucifers (H. schachtii host plants) during the previous five years. At the time of this trial, no beet cyst nematodes were detected in this field. The second test soil (SM) was a Camarillo loam (34\% sand, $42 \%$ silt, $24 \%$ clay, $\mathrm{pH} 7.7$ ) collected near Santa Maria, CA. A majority $(\approx 70 \%)$ of the crops grown in that field during the last 10 years were hosts of $H$. schachtii. The beet cyst nematode population was 15.4 eggs per $g$ of soil. The third soil was the $H$. schachtii-suppressive sandy loam of field 9E described earlier, with a $H$. schachtii population density of 4.9 eggs per $g$ of soil at the initiation of the experiment. All three soils were passed through a screen with 6-mm openings and mixed 10:1 (dry wt/wt) with silica sand. Test soils were fumigated with methyl iodide $(500 \mathrm{~kg} / \mathrm{ha})$. After aeration, the three test soils were each mixed with nontreated $H$. schachtii-suppressive 9E soil to establish dilution ratios of the suppressive soil of $0.0,0.1,1.0,10.0$, or $25.0 \%$ (dry wt/wt).

The soil mixes were placed in plastic cones $\left(120 \mathrm{~cm}^{3}\right.$ in volume, $3.8 \mathrm{~cm}$ in diameter, $20.6 \mathrm{~cm}$ deep; Stuewe and Sons Inc., Corvallis, OR) and seeded with four seeds of mustard greens (Brassica juncea (L.) Czernj. 'Florida broadleaf'; Lockhart Seeds). After emergence, the plants were thinned to one seedling per cone. Four weeks after seeding, each cone was infested with 1,000 J2 of $H$. schachtii. During the first 4 weeks, plants were fertilized with $14 \mathrm{ml}$ of nutrient solution (10 g of Miracle Gro N-P-K [15-30-15] fertilizer per 3.79 liters of water,) weekly. After infestation, each cone received $1.2 \mathrm{~g}$ of slow-release N-P-K (17-6-10) fertilizer (Osmocote, Scotts Co., Marysville, $\mathrm{OH})$. The experiment was incubated in the greenhouse at $24 \pm 3^{\circ} \mathrm{C}$ under ambient light. The experiment was irrigated with tap water as needed. Eleven weeks after infestation, plant tops were cut off, and oven dry weights were determined. Nematode cysts were extracted, and the numbers of beet nematode cysts and eggs were determined.

Data analysis. All data were subjected to analysis of variance. Fisher's protected least significant difference (LSD) was used to separate means at $P=0.05$ if the probability for treatment $F$ was $P<0.05$. The test was performed at $P=0.10$ if the probability for the treatment $F$ was between 0.10 and 0.05 . In the greenhouse experiment of transfer of suppressiveness to fumigated, initially suppressive soil, the regression of the number of eggs per gram of soil to the amount of amendment of suppressive soil $(x i=\log (x+$ $0.01)$ ) was calculated. Data were plotted, and curve fitting was performed. For all other parameters in the greenhouse experiments, Fisher's protected LSD was calculated, and additionally, linear and quadratic contrasts were determined after data transformation $(x i=\log (x+0.01))$.

\section{RESULTS}

Transfer of suppressiveness to fumigated field plots. At the early harvest after 77 days (1,350 DD), the numbers of cysts per

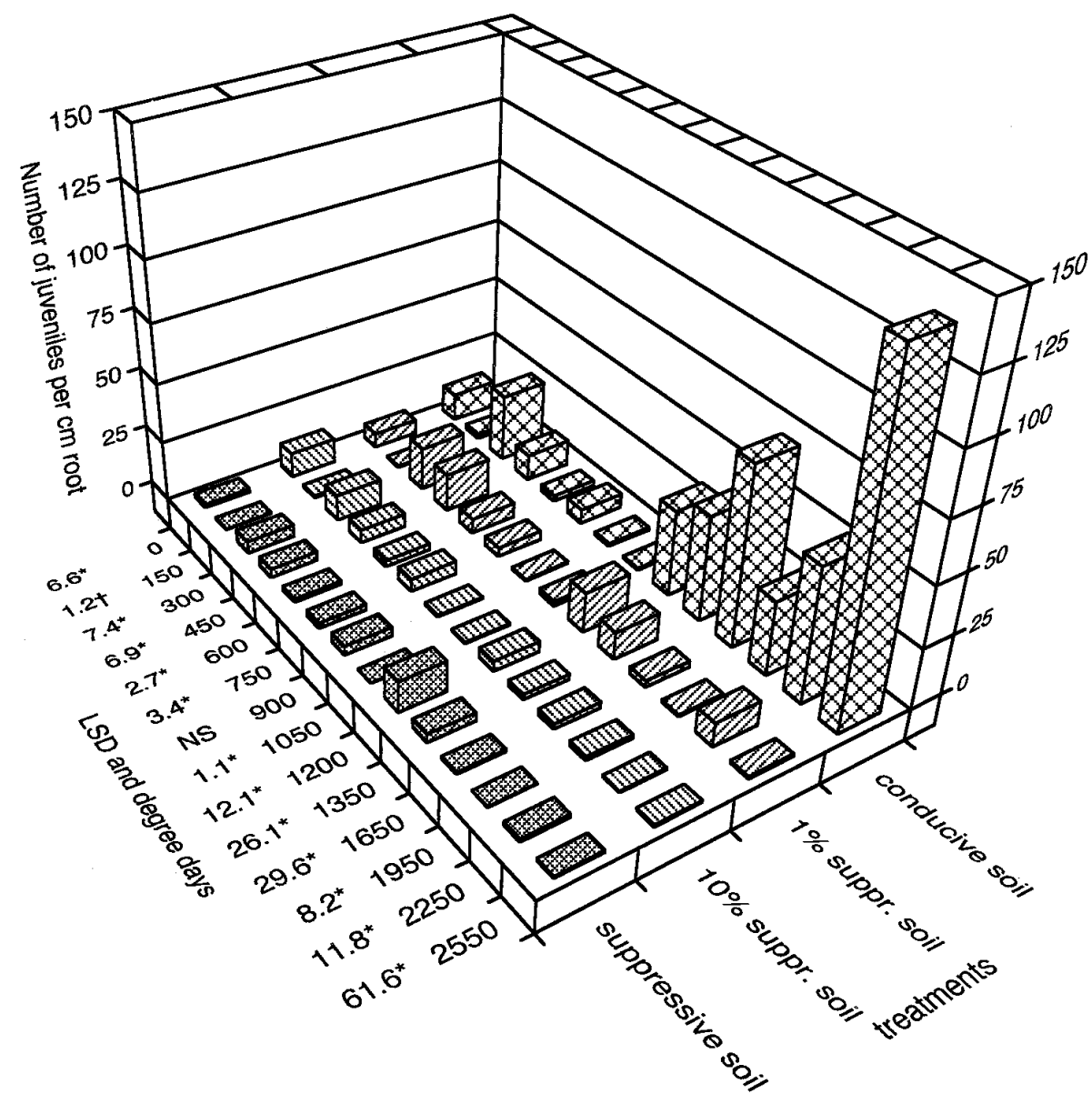

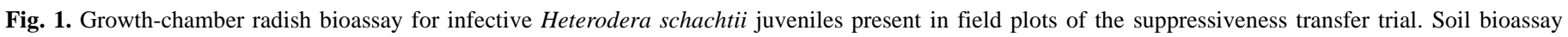

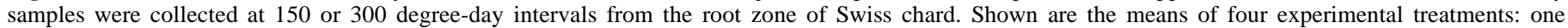

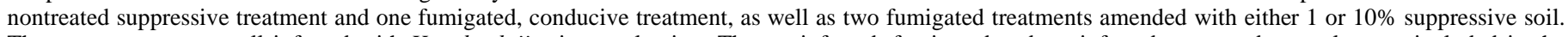

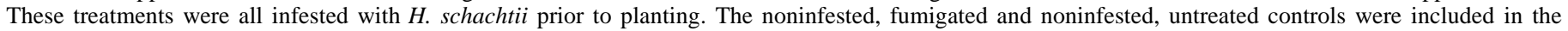
statistical analysis but are not shown. Least significant differences are indicated as $*(P=0.05)$ and $\dagger(P=0.10)$; NS $=$ not significant. 
gram of root dry weight in the treatments with 1 or $10 \%$ soil transfer to fumigated plots were not significantly different from the infested, nonfumigated treatment. The number of cysts per gram of root dry weight was 2.4-fold higher in the infested, fumigated treatment than in the infested, nonfumigated treatment (Table 1). The numbers of eggs per cyst in the $10 \%$ transfer and infested, nonfumigated treatments were not statistically different but were significantly lower than in the infested, fumigated treatment. The number of eggs per cyst in the $1 \%$ transfer was significantly higher than in the $10 \%$ transfer treatment, but significantly lower than in the infested, fumigated treatment. The number of eggs per cyst was 3.4-fold higher in the infested, fumigated treatment than in the infested, nonfumigated treatment.

At the late harvest (2,550 DD), both the 1 and $10 \%$ transfer treatments had low levels of cysts per gram of root dry weight similar to the infested, nonfumigated treatment (Table 1). The number of cysts per gram of root dry weight was significantly higher $(\approx 11.5$-fold $)$ in the infested, fumigated treatment than in the other infested treatments (Table 1). The numbers of cysts per gram of root dry weight in the transfer treatments and the infested, nonfumigated treatment were not significantly different from those in the noninfested, nonfumigated control (Table 1). The number of eggs per cyst was 2.9-fold higher in the infested, fumigated treatment than the average of the 1 and $10 \%$ transfer and infested, nonfumigated treatments.

Monitoring the infectivity of $\mathrm{H}$. schachtii in field plots with the radish bioassay. At planting and both harvest dates for the field trial, the number of $\mathrm{J} 2$ detected in the radish roots of the bioassay were indicative of the suppressive conditions for $H$. schachtii. At planting, the transfer treatments had numbers of $\mathrm{J} 2$ similar to the infested, fumigated treatment. Nine times more J2 were detected in radish roots in the infested, fumigated control than in the infested, nonfumigated control (Fig. 1). At $450 \mathrm{DD}$, the number of $\mathrm{J} 2$ in the $10 \%$ soil transfer treatment was no longer significantly different from that in the infested, nonfumigated treatment. At the early harvest (1,350 DD), the number of J2 was not significantly different in the $10 \%$ soil transfer and infested, nonfumigated treatments. Only in the infested, fumigated control were significantly more $\mathrm{J} 2$ detected by the radish bioassay. At the late harvest (2,550 DD), there was no significant difference among the numbers of $\mathrm{J} 2$ in the transfer treatments and infested, nonfumigated treatment. The number of $\mathbf{J} 2$ in the radish roots in the infested, fumigated treatment

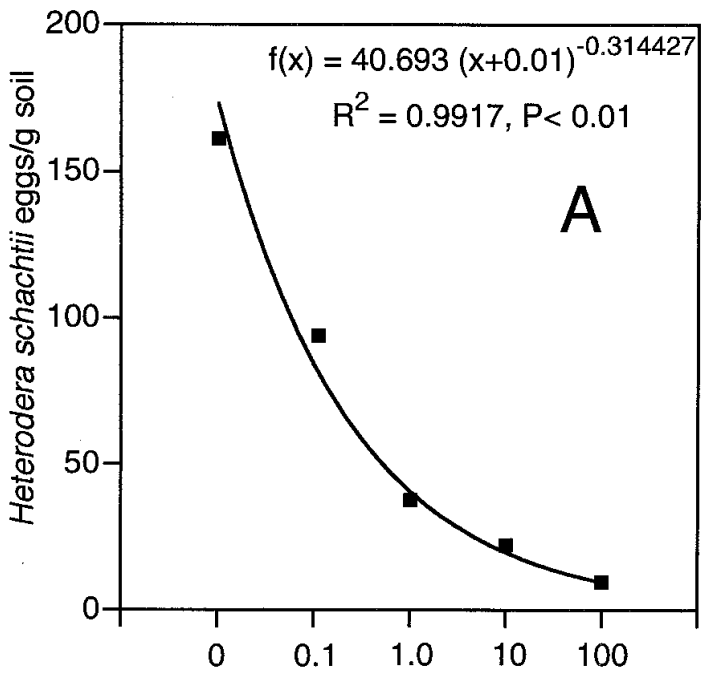

Suppressive soil amendment [\%]

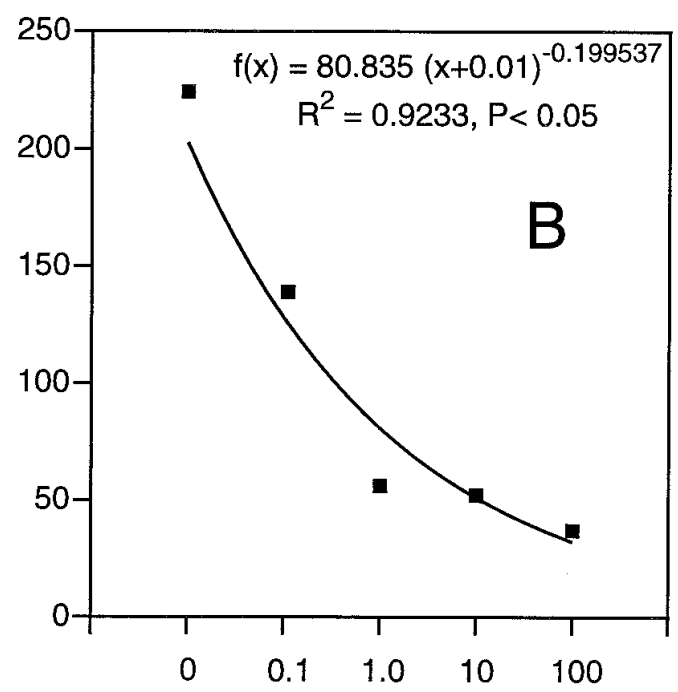

Suppressive soil amendment [\%]

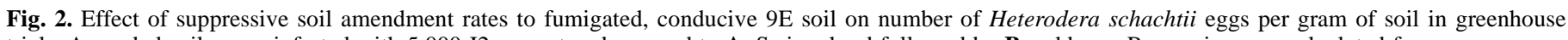

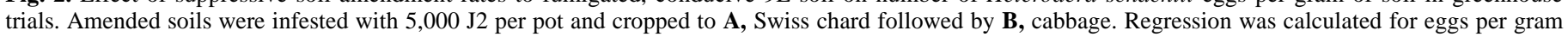
of soil to the log-transformed amendment rate.

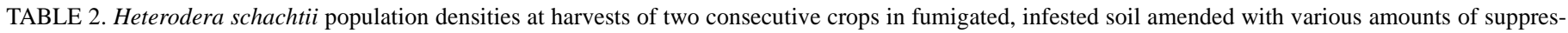
sive $9 \mathrm{E}$ soil in a greenhouse experiment ${ }^{\mathrm{w}}$

\begin{tabular}{|c|c|c|c|c|c|c|c|c|}
\hline \multirow[b]{2}{*}{ Treatment $^{\mathrm{x}}$} & \multicolumn{4}{|c|}{ First crop: Swiss chard } & \multicolumn{4}{|c|}{ Second crop: cabbage } \\
\hline & Plant TDW $(\mathrm{g})$ & Cysts/g soil & Eggs/cyst & $\mathrm{J} 2 / \mathrm{cm}$ & Plant RDW (g) & Cysts/g soil & Eggs/cyst & $\mathrm{J} 2 / \mathrm{cm}$ \\
\hline 0.0 & 6.6 & 1.4 & 113.6 & 3.9 & 0.2 & 2.6 & 91.1 & 22.1 \\
\hline 0.1 & 5.5 & 0.9 & 97.1 & 2.5 & 0.3 & 1.4 & 96.1 & 5.4 \\
\hline 1.0 & 6.7 & 0.7 & 52.2 & 2.0 & 0.3 & 0.9 & 56.0 & 4.2 \\
\hline 10.0 & 4.9 & 0.6 & 35.8 & 0.4 & 0.3 & 0.7 & 71.8 & 0.9 \\
\hline 100.0 & 4.8 & 0.5 & 18.5 & 0.2 & 0.4 & 0.6 & 62.4 & 0.9 \\
\hline LSD $^{y}$ & NS & 0.3 & 29.2 & 2.3 & NS & 0.5 & NS & 9.0 \\
\hline$P$ for treatment $F$ & 0.2114 & 0.0004 & 0.0001 & 0.0291 & 0.5238 & 0.0003 & 0.9326 & 0.0466 \\
\hline \multicolumn{9}{|l|}{ Contrast $^{\mathrm{Z}}$} \\
\hline$P$ linear & 0.0650 & 0.0001 & 0.0001 & 0.0039 & 0.1388 & 0.0001 & 0.5534 & 0.0058 \\
\hline Quadratic & 0.8073 & 0.0194 & 0.3801 & 0.7205 & 0.9150 & 0.0082 & 0.9290 & 0.0938 \\
\hline
\end{tabular}

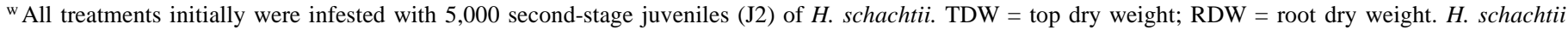
Populations of $H$. schachtii cysts and eggs were measured at harvest. After harvest of the first crop, soils were planted with cabbage without further treatments.

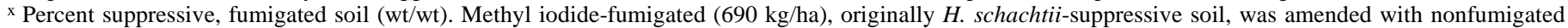
H. schachtii-suppressive soil.

y Fisher's protected least significant difference at $P=0.05$; NS $=$ nonsignificant.

${ }^{\mathrm{z}}$ Orthogonal contrasts were calculated after transformation of soil amendment amount by $x i=\log (x+0.01)$. 
was 180-fold higher than the average in the two transfer treatments and infested, nonfumigated treatment (Fig. 1).

Transfer of soil suppressiveness to fumigated, initially suppressive soil in greenhouse experiments. At the first harvest, soil amended with nematode-suppressive $9 \mathrm{E}$ soil had a significantly lower $H$. schachtii population than the nonamended, fumigated (conducive) control. The interrelation between amount of soil amendment and number of $H$. schachtii eggs per gram soil was described by a significant regression (Fig. 2A). Nematode reproduction in the $10 \%$ transfer treatment was not significantly different from the suppressive control (Table 2). Significantly fewer J2 were detected in the $10 \%$ soil transfer treatment than in the conducive control (Table 2). The amendment amount in suppressive soil had a quantitative suppressive effect on nematode population densities (linear contrast $P=0.05$ ). At the second harvest, all transfer treatments had significantly lower cyst populations than the conducive control with a quantitative effect of soil amendment amount (linear contrast $P=0.05$ ) (Table 2). The number of eggs per gram of soil was described by a significant regression (Fig. 2B). The infectivity of the $\mathrm{J} 2$ was significantly higher in the conducive control than in any other treatment (Table 2). The plant dry weights were not significantly different among the treatments (Table 2).

Transfer of soil suppressiveness to $\boldsymbol{H}$. schachtii-free soil or different textured soil in greenhouse experiments. Amendment of fumigated soils with $H$. schachtii-suppressive 9E soil resulted in fewer numbers of eggs per cyst in all three soils. This effect was significant with $0.1 \%$ suppressive soil amendment in the fumigated, originally suppressive $9 \mathrm{E}$ soil; at $10 \%$ in the sandy loam 9C soil; and at $25 \%$ in the SM loam (Table 3). The number of cysts per $100 \mathrm{~cm}^{3}$ of soil was significantly reduced only in the SM loam at the highest amendment rate.

\section{DISCUSSION}

Biological suppressiveness against $H$. schachtii was transferable with small portions of soil under both field and greenhouse conditions. After 1 month of moist fallow and 77 days of the host crop Swiss chard, $10 \%$ of suppressive soil mixed into methyl bromide-fumigated field plots was sufficient to suppress nematode multiplication to the level of the infested, nonfumigated treatment. After 230 days, $1 \%$ of suppressive soil had transferred the $H$. schachtii suppressiveness to a similar level. At this later date, the plant top dry weights in the $1 \%$ suppressive soil transfer treatment were not significantly different from the noninfested, fumigated control, indicating an efficient protection of the host crop from beet cyst nematode damage. The amounts of soil necessary to transfer cyst nematode suppressiveness were considerably smaller than the ones used for previously reported greenhouse experiments $(19,22)$. The onset of $H$. schachtii suppressiveness was rapid when compared with the transfer of suppressiveness against take-all disease of wheat into fumigated field plots with similar amounts of suppressive soil. After one cropping cycle of wheat, transfer of take-all suppression was not sufficient to keep plants alive until harvest (21). Only in the second year was suppression of the takeall disease attributable to the transfer of suppressive soil (3). Furthermore, the time necessary for the $H$. schachtii suppressiveness to be expressed was significantly shortened when compared with the onset of population density decline under host crops in initially conducive plots in field 9E (25). In those trials, the H. schachtii population level started to decline in the third cropping period of host plants whereas, in the transfer experiments, H. schachtii suppression was observed in the first cropping period.

Measuring the infectivity of $H$. schachtii $\mathrm{J} 2$ in the radish bioassay was valuable for monitoring the development of nematode suppressiveness in different treatments. The infectivity decreased earlier in the $10 \%$ transfer treatment than in the $1 \%$ transfer treatment and remained low for the rest of the monitoring time. Therefore, nematode infectivity seemed to reflect the development of $H$. schachtii suppressiveness. The $1 \%$ soil amendment presumably transferred fewer nematode antagonists into the plots than the $10 \%$ transfer. Whether this was merely a quantitative effect that was the result of introducing fewer propagules of one or more suppressive organisms or also a qualitative difference that was the result of leaving out certain components of a community or population structure, has not yet been determined.

The establishment of $H$. schachtii suppressiveness into fumigated 9E and 9C soil occurred rapidly, presumably because of similar soil texture as well as physical and chemical characteristics. However, the transfer of suppressiveness into the SM soil was more difficult and was achieved only at the highest amendment ratio. The restriction of soil suppressiveness to certain soil textures had been reported for fungal disease-suppressive soils (3). For example, in a study with take-all disease-suppressive soil, it was demonstrated that organisms antagonistic to Gaeumannomyces graminis could be present in a soil with a certain texture without expressing suppressiveness. When the conducive soil was mixed at a rate of $1 \%$ into fumigated soil with a drastically different soil texture that naturally hosted suppressiveness, the disease was diminished (2).

Competitive, slow-growing microorganisms typically dominate natural, undisturbed soil ecosystems (20). Such microorganisms are able to utilize complex carbon sources and compete success-

TABLE 3. Heterodera schachtii population densities 11 weeks after seeding with mustard greens in three fumigated, nematode-infested soils amended with various amounts of suppressive $9 \mathrm{E}$ soil in a greenhouse experiment ${ }^{\mathrm{w}}$

\begin{tabular}{|c|c|c|c|c|c|c|c|c|c|}
\hline \multirow[b]{2}{*}{ Treatment $^{\mathrm{x}}$} & \multicolumn{3}{|c|}{ SL suppressive } & \multicolumn{3}{|c|}{ SL with no cysts } & \multicolumn{3}{|c|}{ Loam with cysts } \\
\hline & RDW (g) & Cysts $/ 100 \mathrm{~cm}^{3}$ & Eggs/cyst & RDW (g) & Cysts $/ 100 \mathrm{~cm}^{3}$ & Eggs/cyst & RDW (g) & Cysts $/ 100 \mathrm{~cm}^{3}$ & Eggs/cyst \\
\hline 0.0 & 2.5 & 80.1 & 40.8 & 2.2 & 35.6 & 120.6 & 2.1 & 149.5 & 94.6 \\
\hline 0.1 & 2.1 & 60.8 & 15.8 & 2.5 & 28.9 & 128.2 & 2.9 & 161.8 & 106.1 \\
\hline 10.0 & 1.6 & 73.1 & 31.0 & 1.4 & 13.9 & 58.9 & 2.8 & 88.6 & 79.3 \\
\hline 25.0 & 1.5 & 67.8 & 20.8 & 1.7 & 23.3 & 42.7 & 2.9 & 70.4 & 61.0 \\
\hline LSDy $^{y}$ & 1.0 & NS & 16.4 & NS & NS & 47.2 & NS & 62.8 & 31.4 \\
\hline $\begin{array}{l}\text { Contrast }^{\mathrm{z}} \\
P \text { linear }\end{array}$ & 0.0296 & 0.5576 & 0.2244 & 0.0485 & 0.1062 & 0.0002 & 0.5700 & 0.0043 & 0.0191 \\
\hline Quadratic & 0.0883 & 0.3475 & 0.0910 & 0.9170 & 0.1598 & 0.1894 & 0.6705 & 0.2724 & 0.0049 \\
\hline
\end{tabular}

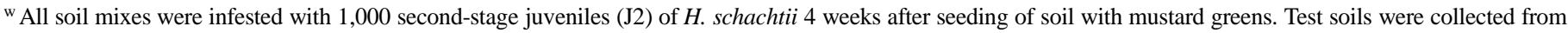
three field sites with either different soil textures or different nematode infestation histories: SL suppressive $=$ sandy loam, originally cyst-nematode suppressive; SL with no cysts $=$ sandy loam, originally no cyst nematodes present; loam with cysts $=$ loam, originally cyst nematodes present. RDW $=$ root dry weight.

${ }^{x}$ Percent suppressive, fumigated soil (wt/wt). All soils were fumigated with methyl iodide (500 kg/ha) before untreated suppressive $9 \mathrm{E}$ soil was added.

y Fisher's protected least significant difference at $P=0.05 ; \mathrm{NS}=$ nonsignificant.

${ }^{\mathrm{z}}$ Orthogonal contrasts were calculated after transformation of soil amendment amount by $x i=\log (x+0.01)$. 
fully with other microbes, often by producing inhibitory metabolites. Microbiostasis can impede microbial colonization $(12,17)$ and may interfere with the activity of nematode antagonists in the nonfumigated soils. This biological phenomenon is active against fungi, bacteria, and actinomycetes (12), and general microbial competition has been considered a core problem in attempts to establish biocontrol organisms $(3,14)$. Alien microorganisms face the challenge of replacing at least parts of native microbial communities that occupy essential resources, and defending their niche with chemical (e.g., antibiotics, siderophores) or physical (e.g., pH, space) means. Autoclaving of soil reduced the microbiostatic effect on introduced microbial organisms (13), and other published research indicates that biocidal disturbances may be crucial to successfully transferring disease suppressiveness $(2,7,9,10,26)$. On the other hand, it is perhaps only indicative of our poor understanding of soil microbial communities, their structure, and interactions that we still have to rely on drastic, nonselective forces to transfer soil suppressiveness to agroecosystems.

\section{ACKNOWLEDGMENTS}

A. Westphal was in part supported by a German Academic Exchange Service-Graduate Scholarship (DAAD, HSP II/AUFE) and the StorkanHanes Foundation. This article is a portion of a dissertation submitted by A. Westphal to the University of California in partial fulfillment of the requirements for the Ph.D. degree. We thank the departments of Nematology and Plant Pathology as well as the agricultural research station, University of California, Riverside, for their support; Drip-In Irrigation Co. and TriCal, Inc. for technical support; and J. Darsow and A. de Bever for technical assistance.

\section{LITERATURE CITED}

1. Alabouvette, C. 1986. Fusarium wilt suppressive soils from the Châteaurenard region: Review of a 10-year study. Agronomie 6:273-284.

2. Andrade, O. A., Mathre, D. E., and Sands, D. C. 1994. Suppression of Gaeumannomyces graminis var. tritici in Montana soils and its transferability between soils. Soil Biol. Biochem. 26:397-402.

3. Baker, K. F., and Cook, R. J. 1974. Biological Control of Plant Pathogens. The American Phytopathological Society, St. Paul, MN.

4. Becker, J. O., Ohr, H. D., Grech, N. M., McGiffen, M. E., Jr., and Sims, J. J. 1998. Evaluation of methyl iodide as a soil fumigant in container and small field plot studies. Pestic. Sci. 52:58-62.

5. Byrd, D. W., Jr., Kirckpatrick, T., and Barker, K. R. 1983. An improved technique for clearing and staining plant tissues for detection of nematodes. J. Nematol. 15:142-143.

6. Caswell, E. P., Thomason, I. J., and McKinney, H. E. 1985. Extraction of cysts and eggs of Heterodera schachtii from soil with an assessment of extraction efficiency. J. Nematol. 17:337-340.
7. Couteaudier, Y., and Alabouvette, C. 1982. Fusarium wilt diseases in soilless cultures. Acta Hortic. 126:133-157.

8. Curi, J., and Zmoray, I. 1966. Beziehung klimatischer Faktoren zur Entwicklungsdauer von Heterodera schachtii in der Slowakei (CSSR). Helminthologia 7:49-63.

9. Furuya, H., and Ui, T. 1981. The significance of soil microorganisms on the inhibition of the macroconidial germination of Fusarium solani f. sp. phaseoli in a soil suppressive to common root rot. Ann. Phytopathol. Soc. Jpn. 47:42-49.

10. Gerlagh, M. 1968. Introduction of Ophiobolus graminis into the new polders and its decline. Neth. J. Plant Pathol. 74(Suppl. 2):97.

11. Goldberg, S. D., and Uzrad, M. 1976. Fumigation of soil strips through a drip irrigation system. HortScience 11:138-140.

12. Ho, W. C., and Ko, W. H. 1982. Characteristics of soil microbiostasis. Soil Biol. Biochem. 14:589-593.

13. Ho, W. C., and Ko, W. H. 1986. Microbiostasis by nutrient deficiency shown in natural and synthetic soils. J. Gen. Microbiol. 132:2807-2815.

14. Jaffee, B. A., Muldoon, A. E., and Westerdahl, B. B. 1996. Failure of a mycelial formulation of the nematophagous fungus Hirsutella rhossiliensis to suppress the nematode Heterodera schachtii. Biol. Control 6: 340-346.

15. Kerry, B. R. 1988. Fungal parasites of cyst nematodes. Agric. Ecosys. Environ. 24:293-305.

16. Kluepfel, D. A., McInnis, T. M., and Zehr, E. I. 1993. Involvement of root-colonizing bacteria in peach orchard soils suppressive to the nematode Criconomella xenoplax. Phytopathology 83:1240-1245.

17. Lockwood, J. L. 1977. Fungistasis in soils. Biol. Rev. Cambridge Philos. Soc. 52:1-43.

18. Menzies, J. D. 1959. Occurrence and transfer of a biological factor in soil that suppresses potato scab. Phytopathology 49:648-652.

19. Nicolay, R., and Sikora, R. A. 1989. Techniques to determine the activity of fungal egg parasites of Heterodera schachtii in field soil. Rev. Nematol. 12:97-102.

20. Pianka, E. R. 1988. Evolutionary Ecology. 9th ed. Harper and Row, Philadelphia.

21. Shipton, P. J., Cook, R. J., and Sitton, J. W. 1973. Occurrence and transfer of a biological factor in soil that suppresses take-all of wheat in eastern Washington. Phytopathology 63:511-517.

22. Stirling, G. R., and Kerry, B. R. 1983. Antagonists of the cereal cyst nematode Heterodera avenae Woll. in Australian soils. Aust. J. Exp. Agric. Anim. Husb. 23:318-324.

23. Westphal, A., and Becker, J. O. 1997. Transfer of suppressiveness against Heterodera schachtii into a fumigated conducive field site. (Abstr.) J. Nematol. 29:614.

24. Westphal, A., and Becker, J. O. 1998. Transfer and establishment of soil suppressiveness against Heterodera schachtii. (Abstr.) Phytopathology 88(suppl.):S96.

25. Westphal, A., and Becker, J. O. 1999. Biological suppression and natural population decline of Heterodera schachtii in a California field. Phytopathology 89:434-440.

26. Wiseman, B. M., Neate, S. M., Keller, K. O., and Smith, S. E. 1996. Suppression of Rhizoctonia solani anastomosis group 8 in Australia and its biological nature. Soil Biol. Biochem. 28:727-732. 